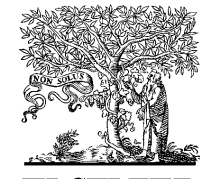

ELSEVIER
Available online at www.sciencedirect.com

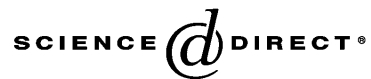

Stud. Hist. Phil. Sci. 36 (2005) 734-743
Studies in History and Philosophy of Science

www.elsevier.com/locate/shpsa

\title{
Arrow's impossibility theorem and the national security state
}

\author{
S.M. Amadae \\ Graduate Faculty of Political and Social Science, New School University, 65 Fifth Avenue, \\ New York, NY 10003, USA
}

Philip Mirowski's essay discussing 'scientific dimensions of social knowledge' is groundbreaking for drawing attention to the peculiar nexus between American Cold War philosophy of science and defense management. In Mirowski's account, analytic philosophy and Operations Research (OR) are intertwined branches of research inseparable from the national security state's mandate to centralize decision-making in the hands of the military or policy elite (see esp. pp. 300-301, 305). As Mirowski's overall argument is too intricate and complex to elaborate in full, I here focus my comments on one single theme of his essay: the manner in which self-proclaimed left-leaning Cold War social scientists inadvertently constructed a command and control theory of political economy and social interactions consistent with the 'negative liberalism' of Hobbes and Nozick, and antithetical to the 'positive liberalism' of Rousseau and Dewey. This underlying theme dovetails with Mirowski's more overt claim that the hallmark of Cold War philosophy of science is the insistence that scientific expertise is independent from social context and entrenched interests.

By the conclusion of his essay, Mirowski frontally critiques what he takes to be a blatant attitude on the part of Operations Researchers, analytic philosophers, and the military that scientific expertise is beyond the fray of partisan politics. His article is characterized by insinuations of social hegemony over scientific discourses; that for example, decision theory 'continues the tradition of seeking political inspiration for the philosophy of science in the same anti-democratic doctrines' found at RAND in the 1960s (p. 320). It remains elusive whether these scientific practices have any internal integrity. If I read Thomas Uebel's paper correctly, it is this question of the interplay between internal standards for evaluating truth claims and leeway for decisions fixed by external parameters that riveted the left wing of the Vienna Circle. It takes a robust philosophy of science to

E-mail address: amadaes@newschool.edu (S. M. Amadae). 
broker between non-arbitrary formal structures to legitimate knowledge and external pragmatic considerations. Mirowski argues that American analytic philosophy, coupled with decision theory and Operations Research, falls short on this count because it presupposes a degree of autonomy in knowledge production that is in practice unattainable.

This philosophical dispute will not be resolved here. My sole aim is to suggest that the scientific discourse broadly construed as OR has rigorous internal structure, and to identify localized points where social context leaves room for contingency. With respect to Operations Research and the US Cold War context, one pointed question is whether there were preexisting theoretical discussions that had already cast the problem of democratic will formation into doubt. Later in this commentary I will argue that, in fact, democratic theory was already in disarray before its further dismemberment at the hands of Operations Researchers. Closely examining the interplay between theory and praxis helps to make clear whether arguments for the minimal Hobbesian state may have garnered strength because they responded to preexisting theoretical challenges characterizing democratic theory, or whether they were promoted by forces intent on subverting democratic will formation. In evaluating this apparent dichotomy it is wise to recall that ever since the French Revolution's decay into Jacobin terror, and in view of Hitler's democratic election to power, leaders and commentators have long wrestled with the potential of popular politics to end in catastrophe. This fear of anarchy, and the ongoing term difficulty of resolving the tensions within democratic theory, therefore legitimately may be cited as reasons buttressing the security oriented minimal state.

Leaving aside John Dewey, Hans Reichenbach and Philip Kitcher, I will elaborate on a pivotal case Mirowski introduces in briefly touching on Kenneth Arrow's impossibility theorem'. ${ }^{1}$ Arrow's status as an Operations Researcher, his internship at RAND during the genesis of the theorem, his inspiration by Alfred Tarski's logic, his tacit assertion that facts and logic are unproblematically objective, the theorem's command and control format coupled with its logical defeat of democratic will formation, all combined with Arrow's left-leaning political commitments, together seem to vindicate Mirowski's claim that in the American Cold War context, political theory and philosophy of science were for all apparent purposes co-opted by forces sympathetic to military stewardship and opposed to participatory democracy. In short, Arrow's densely argued set theoretic treatise demonstrates that there is no way to guarantee a collectively rational expression of individuals' preference rankings over alternatives given several minimal requirements. It is moreover the case that Arrow's depiction of democratic decision-making embodies a command and control format insofar as individual preferences are mechanically amalgamated without communicative discussion of the sort envisioned by Dewey in The public and its problems. ${ }^{2}$ In fact, for Arrow, individuals are best thought of as goal seekers who only interact with each other and use language as a means to maximize personal utility. Therefore, the substance of Arrow's impossibility theorem, and its generation at the military think tank RAND support Mirwoski's overarching claim that American Cold War social science took on an isolationist character mutually exclusive from the domain of either discursive or participatory democracy.

\footnotetext{
${ }^{1}$ Arrow (1951a).

2 Dewey (1988).
} 
To paraphrase Mirowski's argument regarding Arrow (pp. 306-307): The development of the atomic bomb during the Second World War made it imperative in the minds of military leaders and Operations Researchers that democratic decision making was not sufficient to the task of defending the American national security state. The former generation's enthusiasm for democracy, especially apparent in John Dewey's writings, had to be checked by new decision procedures maintained by a community of experts not accountable to public opinion. Operations Researchers rose to this occasion; Kenneth Arrow developed his 'impossibility theorem' which demonstrated that democratic voting respecting individual choice does not necessarily secure collectively rational outcomes. Thus, according to Mirowski, only market expressions of consumer preferences, and expert-based decision procedures, became theoretically sanctioned to establish public will formation. Defense officials were pleased with this finding 'since it suggested that the military was legitimately defending the welfare of the citizenry by allowing them free choice in their purchases while simultaneously conducting the national defense without need for their explicit political acquiescence' (p. 307). This provides a snapshot of Mirowski's thesis as it pertains to how Operations Researchers doubted the efficacy of popular rule in national security matters facing the nation and opted instead for an 'value-free', 'autarkic', 'command and control' scheme for decision-making that obviated the need to consult the populace (pp. 288, 309). Supposedly, by this reading, military commanders appropriated the right to make decisions out of the public eye, while citizens gained autonomy as consumers free to make their own market choices.

Leaving aside that we remain unsure of the characteristic features of 'OR' (other than overlapping with decision theory, analytic philosophy, and potentially neo-classical economics), we can be sure from Arrow's presence in the OR department at Stanford University that he qualifies as a member of this community. ${ }^{3}$ As well, Arrow was at RAND as an intern in the summer of 1948 when he was assigned the task of formulating a utility function for the entire Soviet Union in order to anchor a game theoretic calculation with appropriate payoffs useful to nuclear warfare strategy. This exercise emulated the problem of defining a single business plan for a firm: how can a collective entity have a unified direction if it is comprised of individuals with different interests and perspectives? Thus, it is unquestionable that RAND's isolationist think tank status provided sanctuary for theoretical research outside the breach of public accountability. Given his 'top secret' security clearance issued in 1949 and active through 1971, Arrow is safely regarded as a defense intellectual. Arrow's autobiographical credit to Tarski, who taught a logical course at Columbia University, for the critical insight of representing human rationality as an ordered system of preferences, provides evidence of a direct linkage to the analytic philosophy community. Perhaps most importantly, throughout his career-despite his acknowledgment of the brutal fact that Stalin contravened the promise of socialist emancipation fueling the USSR-Arrow remained committed to what may be best considered politics of inclusion versus politics of control. For example, he was optimistic about democratic socialism, and believed that private property is not a fundamental premise of democratic government. ${ }^{4}$ From this sketch alone, Arrow's professional profile seems to provide

\footnotetext{
${ }^{3}$ For good discussion of the characteristics of OR see Rider (1992).

${ }^{4}$ For discussion see Amadae (2003), p. 183; see also Arrow (1978).
} 
critical mass to Mirowski's thesis: Arrow is a left-leaning theorist with bona fide affiliations to both Operations Research and analytic philosophy who directly claimed in methodological reflection that mathematical logic is the acme of human consciousness and that the goal of social scientific research should be the discovery of universal laws that are independent from cultural context. ${ }^{5}$ Therefore, it is fair to observe that Arrow tacitly endorses the idea that philosophy of science need not concern itself with social forces or interests; the social scientist can be thought of as above the fray of specialized interests. Facts and logic speak for themselves.

Most critically, it is the case that Arrow's famous impossibility theorem proved definitively that collectively rational decisions cannot be reached by democratic voting processes (if one adopts a few minimalist assumptions). That is, given three or more individuals making a collective choice over three or more outcomes, no procedure can be constructed to legitimately represent the public interest. On the surface it seems plausible that Mirowski's thesis is vindicated: a corpus of researchers who can be identified as members of the US Operations Research community participated in building a theoretical foundation for decision-making that centralized power in the hands of a supposedly autonomous and scientific elite. Once rationality is defined as a complete and transitive preference ranking over all alternatives, democratic voting is proven to be inherently unstable and irrational. Moreover, given Arrow's left-leaning credentials, his theoretical blow to cogency of democratic will formation appears to demonstrate, as Mirowski argues, a fundamental subversion of what may be referred to as a deliberative model of democracy from within.

From this overview of Arrow's impossibility theorem, it seems that Mirowski's other claims, such as that American analytic philosophy and social science are insensitive to their connections to social context, should be taken seriously; we can even go further and suspect that the imperatives of the Cold War national security state may have dictated that a command and control version of political economy prevail. We must address where, specifically, in the genesis of the impossibility theorem defense imperatives directly impinged on either the technical details of the result, or its construction in toto. Obviously Arrow would not have developed his impossibility theorem if not presented with the task of deriving a utility function for the USSR while at RAND. Arrow's anti-democratic theorem was nurtured in a defense environment. However, if military soil fertilized Arrow's impossibility theorem, then it remains to be determined whether the technical details of the theorem reflected a military command mindset, or whether more generally this soil solely provided an occasion upon which a theory was formulated that otherwise would not have been. We must establish whether Arrow draws a new theoretical conclusion as a consequence of national security dictates, or whether he was safely working within the confines of a theoretical discussion well under way. Familiarity with the literature rapidly reveals that the impossibility theorem undermining direct democracy was already anticipated both by the eighteenth-century Condorcet paradox, and by the mid-twentieth-century new welfare economics. The first demonstrates that three voters taking a vote over three alternatives can easily reach a deadlock; the second finds that it is impossible to have a value neutral judgment of an optimal social state even if only relying on individual preferences as a starting point.

\footnotetext{
5 Arrow (1951b).
} 
Indeed, the economist E. J. Mishan stated of the theorem that its result was 'hardly surprising' ${ }^{6}$ In many respects, there was little new in Arrow's theorem; in fact it resonated with pre-existing deep doubts about democratic will formation. ${ }^{7}$

We need to assess one-by-one Mirowski's claims supporting his conclusion that Arrow acted as handmaiden for the national security state. 1) 'The relationship of military-organized science to democracy was perhaps the issue most fraught with controversy in the immediate postwar period' (p. 306). This claim requires scrutiny on the basis that first, leaving aside scientific inquiry, democracy is already embattled in any military context for the reason that stealth, surprise, and hierarchy are requisite for successfully executed warfare whereas democracy is dependent upon equality and openness in decision-making. Second, identifying the protagonists in this controversy between 'military-organized science' and 'democracy' is necessary for pinpointing the fault-lines of debate. Thus far, this identification is not sufficiently clear.

2) 'The military and the Operations Researchers shared a jaundiced view of democracy when it came to prosecuting wars, and the suppression of democratic debate over the use of the Bomb was viewed by many in the political classes as a betrayal of fundamental principles which the Bomb was conceived nominally to protect' (ibid.). Mirowski here clarifies that Operations Researchers were keen to promote non-democratic decision technologies to the dismay of 'the political classes'. To support effectively this contention, it is necessary to identify numerous Operations Researchers who directly supported expertise over public discussion in matters of settling the aims of national security. Of course, in pursuing this claim it is necessary to hold that Operations Researchers sought control of social ends, and not only the means to achieve ends once political choices had been made through legitimate democratic channels. This may be the case; however evidence must be supplied to make this counterintuitive case that science should dictate social ends.

Furthermore, to support Mirowski's claim, it is necessary to suppose that military leaders were partial to non-democratic decision procedures both for decisions internal and external to the armed forces. In following the histories of the 1948 genesis of Arrow's theorem, of RAND's 1950s patronage by the US Airforce and the Joint Chiefs of Staff, and RAND alumni's key placements in Robert S. McNamara's Department of Defense (DOD), it is all too apparent that the OR contingent and career military officials, typified by General Curtis LeMay and Admiral Hyman Rickover, are better described as opposing factions. In fact, in assessing McNamara's 1961 takeover of DOD, it is clear that the US military up to that date was not a monolithic entity bent on wresting democratic control from the American public. More significantly, the US military had numerous democratic practices within its own decision procedures. Democratic decision practices within the US armed forces are most visible in the showdown between McNamara and the US Navy and Airforce wherein supposedly relying on RAND's signature decision technology 'systems analysis', McNamara prevailed over the unanimous opposition of the joint chiefs. This landmark TFX fighter decision to build one aircraft serving both Navy and Air Force needs turned into a boondoggle that ultimately rested on a back of an envelop calculation that McNamara deemed superior to the Air Force cost analysts' twenty-seven thousand man hours of assessment. ${ }^{8}$ In short, it is not possible to refer to the US 'military' as a uni-

\footnotetext{
${ }^{6}$ Mishan (1964), p. 61.

7 Mirowski acknowledges this on p. 293; see also Amadae (2003), pp. 83-88, 15-23.

8 Amadae (2003), p. 67.
} 
fied force that was intent on undermining American democracy in favor of a command and control hierarchical decision format.

3) 'Dewey's blind faith in democracy had, therefore, to be revised in the Cold War era' (ibid.). Even Mirowski admits, drawing on Robert Westbrook's comprehensive treatment of John Dewey's views on democracy, that Dewey's attempts to solve inherent tensions within democracy were naive (pp. 296-297). ${ }^{9}$ Mirwoski accedes that Dewey's effort to reconcile scientific and democratic practice, by viewing both as communal practices, to achieve truth in the case of science and consensus on ends in the case of democracy, was 'toothless and nonspecific... [and] proved to be untenable from World War II onwards' (p. 297). In assessing Dewey's contributions to a blueprint for democratic practice, even Mirowski maintains that little was practically relevant to the Cold War political context. That is, he suggests that there were two cogent sets of reasons for the lack of relevance Dewey's political theory had to Cold War America: a lack of internal coherence, and a lack of institutional realism. Therefore, if it is accurate to characterize Dewey as having 'blind faith in democracy', it would seem that the generation prosecuting the Cold War snubbed faith in favor of expediency. All told, these considerations are consistent with concluding that national security imperatives lead to a security-based model for political economy as a safe default. This causal efficacy nowhere rules out that sound reasons, rather than political impulse, prevailed in Cold War construction of the minimal state.

4) 'OR theorists responded to the call, and went to work describing various ways in which democratic decision procedures were "irrational" when it came to momentous choices' (p. 306). Substantiating this claim requires showing that numerous Operations Researchers considered the task of theoretically dismantling democratic voting practices a high priority. Here we get to the heart of what is interesting: was there a inimitable Cold War compulsion to prove that democracy is invalid, and if so, what evidence is requisite to support this claim? Perhaps it is rather the case that democratic theory, much as Mirowski has already pointed out, was embattled on its own accord. Ever since Rousseau's Social contract, and Condorcet's voting paradox, theorists struggled to identify a unified and legitimate public voice amid disparate individuals' concerns. My suggestion is that this question has been as theoretically intractable for Western civilization as has the question of truth in the domain of philosophy of science. It did not have to be theoretically proven that mass politics can lead to irrational outcomes; history adequately demonstrated this. Even if we accept that scientific expertise provided the basis for a new form of paternalism, vindicating Mirowski's thesis would require that Operations Researchers were uniquely sensitive to this issue. Arrow's theorem did not identify new problems with democratic will formation so much as embody acknowledged difficulties in an elegant and precise formal language. ${ }^{10}$

5) 'The most famous of these doctrines produced at RAND was the "Arrow Impossibility Theorem", based directly upon the assumptions of neoclassical economic theory' (ibid.). Much of Mirowski's thesis rests on this statement because Arrow is represented as the decisive Operations Researcher who provided the firepower for relocating authority from the public to experts and military commanders. It is here that Arrow's true colors as an economist, as opposed to an Operations Researcher, are pointed to by Mirowski, and it

\footnotetext{
${ }^{9}$ Westbrook (1991).

${ }^{10}$ For discussion see Amadae (2003) pp. 83-132.
} 
remains unclear what the relationship between neo-classical economic theory and OR is, and which is responsible for the command and control structure of political economy.

Leaving this aside, in resting so much weight on Arrow's theorem for vindicating the argument that Operations Researchers undermined the logical structure of democracy in favor of scientific authority, Mirowski must maintain 6) the upshot of Arrow's theorem is 'that market expression of citizen preferences was a faithful and dependable representation of their desires, whereas standard majority voting procedures were not' (p. 307). Thus, he seeks to conclude that, like Reichenbach's philosophy of science, Arrow's theorem holds that 'scientists were furthering the welfare of citizenry by allowing them free choice in the "products" of their endeavors in the marketplace while conducting their fundamental research without the need for prior accommodation or any explicit political acquiescence' (ibid.). As accurate as Mirowski is in maintaining that Arrow's theorem proves the impossibility of guaranteeing a collectively rational expression of individuals' preferences, he fails to point out that Arrow steadfastly maintained that '[s]imilarly, the market mechanism does not create a rational social choice'. ${ }^{11}$ Arrow is adamantly clear that his theorem applies equally to democratic voting, to establishing a social welfare function, and to the free market: 'Hence, the social good was in some sense to be a composite of the desires of individuals. A view point of this type serves as a justification of both political democracy and laissez-faire economics or at least an economic system involving free choice of goods by consumers and occupations by workers'. ${ }^{2}$

It is in fully coming to terms with this feature of Arrow's theorem that Mirowski's argument - suggesting that Operations Researchers supported the US military in wresting decision control from democratic elections to military planning combined with free marketsis at its weakest. In fact, Mirowski's pointed conclusion that Arrow's theorem vindicates 'market expression of citizen preferences... [as] a faithful and dependable representation of their desires, whereas standard majority voting procedures were not' can only be regarded as a willful misreading of Arrow's theorem. Given that Arrow applies his result with equal force to democratic voting, social welfare and the market, Mirowski loses credibility in asserting that Operations Researchers provided the intellectual basis to ground non-democratic decision procedures. Arrow's theorem, at least not in its initial RAND rendition, cannot be read as supporting either military planning or free markets as legitimate decision means in contradistinction to elections.

This shortcoming in Mirowski's understanding of Arrow's impossibility theorem, however, does not signify that we must or should wholly abandon his project of investigating the means by which Operations Research, the US military, and analytic philosophy helped to construct a negative liberty practice of government excluding participatory democracy. It is solely to suggest that his narrative falls short of providing an adequate explanation of what did end up being the case in the two-decade reception of Arrow's theorem. Over time, first public choice economists, and then economists across the board routinely came to accept that Arrow's impossibility theorem indicts the social welfare function, and democratic voting, while leaving free markets intact. Public choice theorist Charles Rowley is most emphatic on this point: 'Arrow's contribution provides incontrovertible support for mar-

\footnotetext{
11 Arrow (1963), p. 59.

12 Ibid., pp. 22-23; Arrow maintains that each of the conditions that must pertain to a legitimate social choice mechanism as are equally applicable to voting, social welfare function, and the market; for further discussion see ibid., p. 110.
} 
ket process and encouragement for those who seek to constrain the range of collective choice to the limited functions of the minimal state'. ${ }^{13}$

Indeed, if we incorporate the reception of Arrow's theorem into our narrative then we are closer in spirit to Mirowski's thesis which, like Rowley's, claims that Arrow's theorem undermines participatory democracy while simultaneously supporting a negative liberty view of a minimal state consistent with Nozick's Anarchy, State and Utopia (Nozick, 1974). However, if it is the reception of Arrow's theorem that leads to buttressing a minimalist state along the lines of a national security mandate and a free market, then the causal framework laid forth by Mirowski is inadequate to the job of explaining or even describing the new form of American Cold War political economy.

The task at hand provoked by Mirowski's essay is to discover an alternative narrative. I believe that in order to make progress, it is essential to perform our best balancing act in honoring the integrity of scientific discourses against acknowledging that they occur within brick and mortar institutions with flesh and blood researchers. Respecting the genesis and reception of Arrow's impossibility theorem, this requires paying strict attention to the state of the art of democratic theory and social welfare economics from Arrow's vantage point in developing the theorem, and in identifying the novelty of Arrow's signature contribution to late twentieth-century political theory. In becoming clear that Arrow's impossibility theorem was anticipated by at least two earlier results, the eighteenth-century Condorcet paradox which cast doubt on the collective rationality of democratic voting procedures, and the new welfare economics which all but demonstrated that there is no meaningful way to generate a collective statement of social wellbeing, it is a more difficult to make the case that Arrow was pressured by national security imperatives in deriving his impossibility theorem. It is more helpful to proceed by accepting that democratic voting procedures had long been recognized to present challenges for representing an unequivocal statement of popular will.

There are at least three points of note in examining the reception of Arrow's theorem. First, Arrow steadfastly, throughout his career, maintained that his theorem indicted markets equally to democracy and social welfare as a means of achieving collective outcomes. It is difficult to see any means by which the theorem could be interpreted to support either free markets or military planning over democracy. To locate in Arrow's theorem a mandate for the national security state would require focusing on its reception. Notably, within the vast social choice literature, there is little attempt to pursue the question of whether the market may accurately be deemed a social choice mechanism subject to Arrow's theorem.

Second, it was James Buchanan, who would later facilitate the growth of the public choice community, who provided the strong interpretation that Arrow's theorem vindicates markets while throwing into doubt collective will formation in the form of social welfare. Buchanan's 1954 paper capitalized on Arrow's theorem to draw the definitive conclusion that there can be no meaningful statement of public interest, and no meaningful concept of the public. ${ }^{14}$ Simultaneously, he argued that markets stand intact regardless of Arrow's theorem for the simple reason that markets have no pretense to serve the public interest; their main merit is rather to preserve the sanctity of individual choice.

\footnotetext{
13 Rowley (1993), p. xiii.

14 Buchanan (1954), pp. 114-123.
} 
Third, acknowledging the public choice role in establishing the consensus that Arrow's theorem is pro-market and anti-democratic, we must reassess the supposedly pivotal role that Operations Researchers played in neutralizing participatory democracy for the reason that public choice scholars do not overlap with the Operations Research community. This observation is factual and intuitive insofar as Operations Research command and control countenance is antithetical to public choice theorists' disdain for planning of any kind.

In concluding, although Mirowski has broken new ground in his essay looking to understand the military's role in establishing a norm of a minimal state coupled with military authoritarianism, the details configuring this ground need greater resolution. Mirowski seeks to support a pro-discursive democracy stance by showing how negative liberalism was forged by might rather than persuasive argumentation.

As important as are the aims and insights offered by 'The scientific dimensions of social knowledge and their distant echoes in 20th-century American philosophy of science', it would be helpful if two separate lines of argumentation were disentangled, thereby doing each greater justice. First, of course it is key to recognize how social forces impact theoretical endeavors, and this observation would seem even more obvious respecting decision technologies with public policy implications. However, second, even in exposing the military's complicity in building the foundation of a minimalist national security state, this exposé is insufficient for offering an alternative blueprint for social organization. Mirowski's apparent frustration with non-participatory means of government combined with a global regime of capitalism, cannot be assuaged without a clearer conception of the division of labor between rigorous argumentation and social contingencies. Even if we agree that the national security mandate first permitted the creation of Arrow's theorem, and subsequently paved the way for a contrary reading of the theorem, such a line of inquiry is insufficient to the task of debating with theorists in the field who must be persuaded through reasoned argument. Thus, for example, when Mirowski remarks offhand that Amartya Sen's version of political economy can never amount to more than negative liberalism, it is unclear what his argument strategy is and how he hopes to be effective:

It should be noted that RCT [rational choice theory] and Deweyan Pragmatism are congenitally incompatible. Any appeals by RCT to developmental notions of democracy are fundamentally spurious: it is as static as a politics as Walrasian theory turned out to be a static economics. A careful elaboration of this point would demonstrate why Amartya Sen's version of political economy is ultimately incoherent and self-defeating. ${ }^{15}$

Scientific discourses of rational choice theory, social choice theory, and public choice theory did stem directly from Arrow's RAND-inspired impossibility theorem, yet pointing to this origin will not and cannot replace the need for defeating arguments for the minimalist state on their own terms. Like it or not, negative liberalism has the weight of historical experience and theoretical argument behind it, even as it provides a good strategic fit in a nuclear era wherein elites worry about domestic and international expressions of republican self-rule. Alternatives, if they are to be forthcoming, need to be rigorously defended, or they can be attacked on the same basis that Mirowski disapproves of the autarky of

15 Mirowski (forthcoming). 
philosophy of science: for being forged out of arbitrary will instead of decentralized consensual concurrence.

\section{References}

Amadae, S. M. (2003). Rationalizing capitalist democracy: The Cold War origins of rational choice liberalism. Chicago: University of Chicago Press.

Arrow, K. (1951a). Social choice and individual values. New York: Wiley.

Arrow, K. J. (1951b). Mathematical models in the social sciences. In D. Lerner, \& H. Lasswell (Eds.), The policy sciences: Recent developments in scope and method (pp. 129-154). Stanford: Stanford University Press.

Arrow, K. J. (1963). Social choice and individual values (2nd ed.). New Haven: Yale University Press.

Arrow, K. J. (1978). Comments on Capitalism, socialism, and democracy. Commentary, 65(4), $29-31$.

Buchanan, J. M. (1954). Social choice, democracy, and free markets. Journal of Political Economy, 62, 114-123.

Dewey, J. (1988). The public and its problems. Chicago: Swallow Press.

Mirowski, P. (forthcoming). Sleights of the invisible hand: Economists' interventions in political theory. Journal for History of Economic Thought.

Mishan, E. J. (1964). Welfare economics: Ten introductory essays (2nd ed.). New York: Random House.

Nozick, R. (1974). Anarchy, state, and utopia. Oxford: Blackwell.

Rider, R. (1992). Operations Research and game theory: Early connections. In E. R. Weintraub (Ed.), Toward a history of game theory (pp. 225-240). History of Political Economy, 24 (Suppl.). Durham, NC: Duke University Press.

Rowley, C. K. (1993). Introduction. Social choice theory, Vol. 1. The aggregation of preferences. Aldershot: E. Elgar.

Westbrook, R. B. (1991). John Dewey and American democracy. Ithaca: Cornell University Press. 